\title{
ATIVIDADE REFLEXIVA E REGULAÇÃO DA CONDUTA: UM ESTUDO SOBRE CRIANÇAS COM BAIXO RENDIMENTO ESCOLAR'
}

\author{
REFLECTIVE ACTIVITY AND BEHAVIOURAL ADJUSTMENT: A STUDY OF CHILDREN WITH POOR \\ ACADEMIC PERFORMANCE
}

Mônica Dorrenbach Luna²

\begin{abstract}
RESUMO
O presente estudo teve como objetivo diagnosticar as condições da atividade reflexiva e da regulação de conduta em crianças com baixo rendimento escolar e compará-las com as condições de crianças com alto rendimento escolar. Doze crianças, seis de cada grupo de rendimento escolar, foram entrevistadas e realizaram três tarefas individuais na própria escola, em ambiente reservado. Dentre as análises que permitiram o diagnóstico pretendido, a análise das diferenças intergrupais evidenciou que o aspecto da atividade reflexiva sobre os conceitos científicos é característico do grupo avaliado e relevante para a compreensão do conjunto das condições psicológicas examinadas.
\end{abstract}

Palavras-chave: rendimento escolar; auto-regulação; atividade reflexiva.

\begin{abstract}
The purpose of this research was to diagnose conditions relating to reflective activity and behavioural adjustment in children with poor academic performance, comparing them with children with a high level of academic performance. Twelve children, six from each performance group, were interviewed and carried out three individual tasks within the school itself, in a closed environment. Among the analyses that enabled the desired diagnosis to be achieved, the analysis of inter group differences showed that the aspect of reflective activity on scientific concepts is characteristic of the group assessed and is relevant for the understanding of the universe of psychological conditions examined.
\end{abstract}

Key words: academic performance; self-adjustment; reflective activity.

A literatura aborda a incongruência entre os quadros clínicos de dificuldade de aprendizagem, delineados pelos especialistas, e aqueles assim rotulados pela escola (Dantas, 1981; Sucupira, 1986; Cypel, 1986; Masini, 1986; Wong, 1986). Definidas pela comunidade científica como desordens neuro- psicológicas dissociadas de deficiências físicas, sensoriais ou mentais, assim como de diferenças culturais e de inadequação instrucional (García, 1998, p. 31-32), as dificuldades de aprendizagem apontadas pelas escolas não apresentam critérios tão específicos ou consensuais. A literatura sobre o fenômeno da não-aprendizagem recomenda que as investigações do tema recusem a proposta de equivalência entre distúrbio de aprendizagem - learning disabilities - (García, 1998), de natureza específica, e a condição mais inespecífica do baixo rendimento escolar (Wong, 1986; Senf, 1986), evitando assim o enviesamento de amostragem e de resultados.

As dificuldades identificadas pelas escolas comportam, muitas vezes, prejuízos intelectuais cujas características concentradas, comuns a várias crianças, sugerem a qualidade instrucional como possível variável de efeito significativo. De alguma forma, o ensino poderia estar favorecendo esta qualidade de aprendizagem pois, há muito tempo, teóricos da Psicologia da Educação compreendem que os processos do ensino e da aprendizagem são

\footnotetext{
${ }^{1} \mathrm{O}$ presente artigo de pesquisa resume a investigação realizada pela autora no Programa de Mestrado em Educação da Universidade Federal do Paraná entre 1997 e 1999, com apoio financeiro da CAPES (bolsa de demanda social).

${ }^{2}$ Psicóloga, mestre em educação e professora substituta do Departamento de Psicologia da Universidade Federal do Paraná. monicaluna@uol.com.br.
} 
interdependentes (Rocha,1980). Ou seja, a similaridade das dificuldades cognitivas, verificada na maioria das crianças de escola pública que chegam à clínica, assim como o perfil endêmico das dificuldades de aprendizagem identificadas nas instituições educativas, sugere uma reflexão acerca do que vem sendo feito em sala de aula para a superação destes quadros ou, ainda antes, para gerá-los ou provocar sua persistência.

A natureza das queixas formuladas pela escola também estimulava o questionamento sobre a gênese das dificuldades de aprendizagem. Uma concepção do desenvolvimento como correlato ao rendimento escolar parece sustentar a identificação escolar das D.A. (dificuldades de aprendizagem). Detectadas em meio ao processo ensino-aprendizagem, tais dificuldades são designadas por termos que remetem imediatamente a desordens do desenvolvimento orgânico, psicomotor, cognitivo e/ou da personalidade (como desnutrição, hiperatividade, dislexia, apatia, entre outras). Esta idéia, por sua vez, sugere a "correção" do indivíduo por especialistas do desenvolvimento para que haja melhora no aproveitamento escolar. Descartase, assim, a verificação do contexto e das condições do processo ensino-aprendizagem, como sugere a noção de problema de aprendizagem. Tudo se dá como se houvesse forte correlação entre as avaliações tradicionais de rendimento escolar e as do desenvolvimento, suposição que justifica tal encaminhamento.

Reconhecendo que há determinações socioculturais e psicológicas no fracasso escolar, a intervenção do psicólogo deve se dirigir ao favorecimento da conscientização institucional das circunstâncias que geram o insucesso (Machado \& Souza, 1997) e, paralelamente, à elaboração de procedimentos psicopedagógicos que auxiliem o professor na superação dos entraves das crianças mal sucedidas (Bassedas et al., 1996) e no avanço qualificado da totalidade do grupo discente. Eis aí o esboço de uma psicologia que se faz historicamente necessária, e à qual se dedicou este estudo.

\section{PRESSUPOSTOS E REFERENCIAL TEÓRICO}

A noção de interdependência entre o processo ensino-aprendizagem e o desenvolvimento (Merani, 1972; Piaget, 1964), própria da concepção interacionista e a ação mediadora dos objetos da cultura, historicamente constituídos, no movimento evolutivo da dimensão interpsicológica para a dimensão intrapsicológica (Vigotsky, 1984), central na concepção histórico-cultural, são os pressupostos orientadores deste estudo.

O processo ensino-aprendizagem foi concebido como um fenômeno tridimensional, no qual a consciência é meta sine qua non. Uma primeira dimensão refere-se à atividade de aprendizagem, seus objetivos, seus motivos (Leontiev, 1978); outra dimensão do fenômeno se concretiza no encaminhamento das formas de relação entre as crianças e entre as crianças e os adultos durante a atividade de aprendizagem, ou seja, nas interações sociais escolares (Gil, 1993; Branco, 1993). Por fim, encontram-se os processos psicológicos do aprendiz, dos quais tentou se aproximar este estudo.

A consciência é o fenômeno central deste estudo, diretamente envolvido com os processos psicológicos em questão.

Considerando o referencial histórico-cultural ençntrado em Leontiev (1978), a consciência tem sua gênese na divisão social do trabalho. É, inicialmente, um reflexo psíquico que impulsiona o sujeito a realizar parte da atividade, compreendendo e tolerando a postergação do atendimento de sua(s) necessidade(s). A linguagem, por sua vez, surge da necessidade de compartilhar significados durante esta divisão da atividade coletiva. Mais tarde, a atividade da consciência torna-se um reflexo psíquico mais geral, destacado de outros mais diretamente derivados da realidade concreta, vindo a compor um sistema interfuncional.

A atividade da consciência possibilita, entre outras coisas, a discriminação das impressões interiores e a observação de si mesmo, ação própria da dimensão reflexiva da consciência, analisada neste estudo. Ou seja, a consciência reflexiva é a função psicológica que se ocupa da auto-percepção das diferentes atividades da mente, permitindo sua classificação, seu isolamento e controle. É consolidada no processo de intelectualização (significação, abstração e generalização) que se dá durante a formação dos conceitos científicos, apresentados pela escola. A intelectualização e a consciência dos processos mentais, por sua vez, engendram um crescente domínio voluntário sobre o próprio psiquismo (Vigotsky, 1987). Desta forma, outro processo enfocado neste estudo é o de auto-regulação. 
Trata-se do processo psicológico de regulação deliberada da conduta. Inclui planejamento, monitoração e avaliação dos resultados da conduta pelo próprio sujeito (Luria, 1987; Díaz, Neal \& Amaya-Williams, 1993). Tem sua gênese nas interações sociais, sendo a linguagem o instrumento que medeia a internalização dos comandos da conduta voluntária. Sua consolidação se dá com o uso da percepção generalizante, gerada pela consciência reflexiva na elaboração conceitual.

É possível observar que a fundamentação teórica adotada foi extraída basicamente da psicologia soviética (Vigotsky, Leontiev, Luria) e de seus intérpretes (Díaz et al., 1993). No entanto, alguns conceitos nascidos em quadros teóricos distintos parecem apresentar interfaces com os processos estudados. Tais conceitos merecem uma análise comparativa aprofundada e rigorosa, o que não foi realizado neste estudo. São eles: tomada de consciência (Piaget, 1977; 1978) - ativação da consciência para compreender a ação e elaborar o conceito; metacognição (Lawson, 1984; Kirby, 1984) - percepção reflexiva e controle dos próprios processos cognitivos e conscientização (Freire, 1983) - captação crítica da realidade possibilitada pela organização reflexiva do pensamento.

Para atingir o objetivo proposto - diagnosticar as condições da atividade reflexiva e de auto-regulação de crianças com história escolar de insucesso - foram comparados estudantes com diferentes rendimentos escolares, disponibilizando, assim, dados suficientes para uma análise e para discussão.

\section{METODOLOGIA}

\section{- Sujeitos}

Para a investigação foram selecionados doze alunos do Ensino Fundamental de uma escola municipal de Curitiba. Seis alunos (cinco meninos e uma menina) de uma mesma classe de aceleração de estudos com, ao menos, dois anos de atraso escolar, foram caracterizados como tendo baixo rendimento escolar. Cinco cursavam nível escolar de segunda série, tendo dez anos de idade e um aluno cursava o nível escolar de terceira série, tendo onze anos. Além de se encontrarem inscritos na mesma classe do programa de aceleração de estudos (adequação série-idade), cujo critério de participação era, essencialmente, o atraso escolar, para garantir o critério exclusivo de baixo rendimento, todos os sujeitos selecionados ingressaram na escola em idade regular e tiveram freqüência suficiente nos anos letivos cursados.

Dos seis alunos com alto rendimento escolar, quatro eram meninas e dois eram meninos com notas iguais ou acima de 80,0 (oitenta) em todas as matérias, durante o ano letivo de 1998. Todos cursavam a terceira série, três com oito anos e três com nove anos de idade.

\section{- Procedimentos de coleta e registro de dados}

Os procedimentos de coleta e registro de dados foram realizados em um encontro individual, em sala reservada, na escola onde foram selecionados os sujeitos do estudo.

O conjunto final de instrumentos para a coleta de dados foi aplicado em uma única sessão, com aproximadamente sessenta minutos de duração, e foi composto de uma entrevista semi-aberta seguida de três tarefas para resolução: um problema lógico, um quebra-cabeça e uma tarefa pedagógica.

Após uma breve conversa com o objetivo de deixar o aluno à vontade, a orientação geral para iniciar a sessão foi a seguinte: Estou fazendo uma pesquisa com crianças e preciso de sua ajuda para responder a algumas perguntas e para fazer algumas atividades. Nada disso vai ficar aqui na escola, nem vale nota. 
1) A entrevista: para iniciar a entrevista a orientação dada foi a seguinte: eu vou fazer algumas perguntas porque estou interessada em saber algumas coisas que as crianças pensam e como entendem o que acontece dentro da cabeça na hora de aprender. O roteiro era o seguinte:

O que é inteligência? Você acha que é inteligente? Alguém pode ser mais inteligente do que já é? O que é aprender? Como você faz para aprender alguma coisa? Como você sabe se aprendeu alguma coisa ou não? Quais matérias você tem na escola? Por que você acha que estão divididas assim? Se você fosse explicar para alguém que nunca estudou, como você explicaria o que é português? E matemática? E ciências? E história? E geografia?

2) O problema lógico: Orientação: Aqui tem um problema diferente para você resolver. Primeiro leia bem o que está escrito.

Problema Lógico: Carlos, Janete e Valéria têm cachorros de raças diferentes. Usando as dicas abaixo, você poderia descobrir o nome de cada cachorro, sua raça, e à qual criança ele pertence?

1. Fofão é o pastor alemão.

2. Carlos é o dono do dálmata, que não se chama Roque.

3. O cachorro de Janete não é o fila.

4. Um dos cachorros se chama Jojoba.

\begin{tabular}{||l|l|l||}
\hline NOME DO CACHORRO & RAÇA DO CACHORRO & NOME DA CRIANÇA \\
\hline & & \\
\hline & & \\
\hline & & \\
\hline
\end{tabular}

Após a checagem da compreensão da tarefa foi realizado o inquérito anterior à resolução: Como você vai fazer para resolver este problema?

Em seguida à sua resposta, o sujeito foi recomendado a iniciar a resolução: Agora você pode usar o lápis e a borracha para ir resolvendo. Você pode conversar comigo enquanto faz, se quiser.

Encerrada a resolução, foi realizado o inquérito posterior: Como você fez para descobrir ou as respostas? Ou, no caso de quem entregou sem responder: Como você fez para tentar resolver o problema?

3) O quebra-cabeça: Orientação: Aqui tem um quebra-cabeça para você resolver. Você está vendo esta arrumação de palitos de fósforo? Então, você tem que formar 3 quadrados de tamanhos iguais mexendo só 3 palitos e não pode sobrar nenhum palito fora dos quadrados, certo?

\section{Quebra-Cabeça}

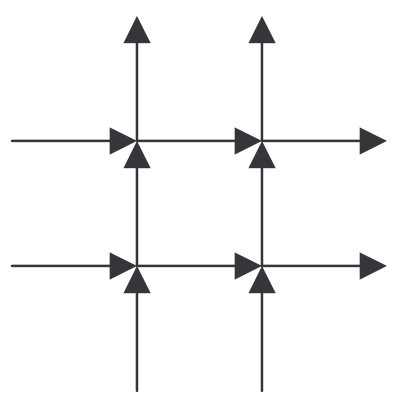

Após a checagem da compreensão da tarefa foi realizado o inquérito anterior à resolução: Antes de começar a mexer me explique como você vai fazer para resolver este problema? 
Em seguida à sua resposta, o sujeito foi recomendado a iniciar a resolução: Agora pode ir tentando fazer os quadrados, lembrando da regra. Você pode conversar comigo enquanto faz, se quiser. Você pode tentar até quando quiser.

Encerrada a resolução, foi realizado o inquérito posterior: Como você fez para descobrir? Ou, no caso de quem não achou a solução: Como você estava tentando descobrir?

4) A tarefa pedagógica: Orientação: Eu pedi para o pessoal da escola montar uma tarefa com assuntos que vocês estudam aqui na escola. Não vale nota e eu não vou corrigir nem dizer se está certo ou errado porque estou mais interessada em ver como você faz do que o quê você fez. Você decide o que pode, ou não, responder. Pode falar comigo enquanto faz e pedir ajuda, se precisar.

\section{Tarefa Pedagógica}

\section{Pipa}

É também conhecida por: arraia, raia, pandorga, papagaio, quadrado. A pipa foi inicialmente usada como símbolo religioso: içada ao céu para entrar em contato com os deuses, era utilizada para determinadas predições e para proteger as colheitas.

A pipa é muito popular, tanto entre os adultos como entre os meninos.

Antes de ser um brinquedo, a pipa também serviu para experiências científicas: Benjamin Franklin, inventor do pára-raio, usou-a para estudar a eletricidade da atmosfera e Guilherme Marconi aproveitou-a como antena para seus experimentos de radiotransmissão.

ENCICLOPÉDIA JUVENIL. São Paulo, Abril, v. 3, p. 231.

1) Responda com suas palavras:

a) De acordo com o texto, para que já foi usada a pipa?

b) Qual dos nomes, dados à pipa no texto, você utiliza sempre?

2) Coloque as palavras abaixo em ordem alfabética:

RAIA - PANDORGA - BRINQUEDO - PIPA - CÉU - DEUSES - ADULTOS

3) Meu livro tem 375 páginas. Já li 129 páginas. Quantas ainda faltam para eu ler?

4) Comprei 1 centena de laranjas, 5 dezenas de maçãs e 9 abacaxis. Quantas frutas comprei?

5) Resolva:

$$
\begin{array}{ll}
225+142= & 284-134= \\
15: 3= & 210 \times 4=
\end{array}
$$

6) Por que devemos ferver o leite?

7) O que é erosão?

8) Que tipo de trabalho faziam os escravos nas cidades antigas?

Os dados coletados pela entrevista e pela resolução de tarefas foram simultaneamente gravados e filmados. As entrevistas foram transcritas na íntegra, servindo a filmagem como apoio ao registro fonográfico. No caso das tarefas, apenas as falas das situações de resolução de problemas foram transcritas para auxiliar na análise. Quanto às condutas no decorrer das tarefas, apenas aquelas sinalizadas por constituírem indicadores de análise foram transcritas, partindo de sua videografia e com auxílio do registro fonográfico.

\section{- Procedimentos de análise dos dados}

Os dados foram submetidos à análise visando captar possíveis padrões, evidências de concepções e/ou condutas típicas de determinado sujeito e/ou grupo, à luz do quadro teórico adotado.

Durante o processo de análise, os dados foram abordados sob diferentes perspectivas. Cortes transversais (uma mesma atividade de diferentes sujeitos) e longitudinais (ao longo das atividades de um mesmo sujeito), por conteúdo produzido (tipo de resposta, de erros, técnicas de apoio registradas) e processo observado (tempo de trabalho, uso da fala, grau de independência, recursos intelectuais usados) foram realizados na tentativa de identificar regularidades individuais e/ou grupais. 
Para análise da consciência reflexiva, foram expressivos alguns dados obtidos nas respostas verbais e nas condutas dos sujeitos durante a situação de entrevista. Para análise do processo de auto-regulação foram considerados alguns dados obtidos nos planos (anteriores) e nas descrições (posteriores) verbais da atividade, solicitados nas situações do problema lógico e do quebra-cabeça, assim como dados extraídos do restante das condutas verbais durante as situações do problema lógico e do quebra-cabeça.

As categorias mais abrangentes de análise (consciência reflexiva e auto-regulação) foram pré-estabelecidas pela literatura discutida anteriormente (Vigotsky, 1982 e Luria, 1987). As categorias mais específicas (ativação da consciência reflexiva, atividade reflexiva sobre intelecto e atividade reflexiva sobre conceito científico), as subcategorias, com exceção do nível de regulação da fala (Luria, 1987), e os indicadores correspondentes foram pósestabelecidos, evidenciados pelo exame dos dados, e são apresentados nas Tabelas 1 e 2 .

Tabela 1: Categorias e indicadores de análise da consciência reflexiva

\begin{tabular}{|c|c|c|c|c|c|}
\hline \multicolumn{6}{|c|}{ CONSCIÊNCIA REFLEXIVA } \\
\hline \multirow{2}{*}{$\begin{array}{c}\text { Categoria } \\
\begin{array}{c}\text { Sub- } \\
\text { categoria }\end{array}\end{array}$} & \multirow{2}{*}{$\begin{array}{c}\text { Ativação da } \\
\text { consciência } \\
\text { reflexiva }\end{array}$} & \multicolumn{3}{|c|}{ Atividade reflexiva sobre intelecto } & \multirow{2}{*}{$\begin{array}{c}\text { Atividade } \\
\text { reflexiva sobre } \\
\text { conceito } \\
\text { científico } \\
\text { Abstração } \\
\text { conceitual }\end{array}$} \\
\hline & & $\begin{array}{c}\text { Generalização } \\
\text { do conceito de } \\
\text { atividade } \\
\text { intelectual }\end{array}$ & $\begin{array}{c}\text { Consciência } \\
\text { da própria } \\
\text { atividade } \\
\text { mental }\end{array}$ & $\begin{array}{l}\text { Natureza do } \\
\text { conceito de } \\
\text { intelecto }\end{array}$ & \\
\hline $\begin{array}{c}\text { Indicadore } \\
\text { s }\end{array}$ & $\begin{array}{c}\text { Providência } \\
\text { de resposta } \\
\text { às perguntas; } \\
\text { prontidão ou } \\
\text { hesitação } \\
\text { para } \\
\text { providenciar } \\
\text { respostas }\end{array}$ & $\begin{array}{c}\text { Presença de } \\
\text { termos gerais } \\
\text { ou relativos a } \\
\text { experiências } \\
\text { particulares na } \\
\text { formulação dos } \\
\text { conceitos }\end{array}$ & $\begin{array}{l}\text { Referência a } \\
\text { procedimento } \\
\text { s } \\
\text { psicológicos } \\
\text { (internos) } \\
\text { e/ou técnicos } \\
\text { (externos) }\end{array}$ & $\begin{array}{c}\text { Presença de } \\
\text { características } \\
\text { de variabilidade } \\
\text { e possibilidade } \\
\text { de controle da } \\
\text { inteligência, do } \\
\text { processo de } \\
\text { aprendizagem } \\
\text { e de seus } \\
\text { resultados }\end{array}$ & $\begin{array}{l}\text { Presença e } \\
\text { natureza de } \\
\text { critérios de } \\
\text { distinção } \\
\text { conceitual das } \\
\text { diferentes } \\
\text { áreas de } \\
\text { conhecimento } \\
\text { (matérias) }\end{array}$ \\
\hline
\end{tabular}


Tabela 2: Categorias e indicadores de análise da auto-regulação

\begin{tabular}{|c|c|c|c|c|c|}
\hline \multicolumn{6}{|c|}{ AUTO-REGULAÇÃO } \\
\hline Categoria & $\begin{array}{l}\text { Função reguladora } \\
\text { da fala }\end{array}$ & \multicolumn{4}{|c|}{ Regulação da conduta } \\
\hline $\begin{array}{l}\text { Sub- } \\
\text { categoria }\end{array}$ & $\begin{array}{c}\text { Nível de regulação } \\
\text { da fala }\end{array}$ & $\begin{array}{l}\text { Antecipação } \\
\text { verbal de } \\
\text { ações } \\
\text { estratégicas }\end{array}$ & $\begin{array}{l}\text { Consciência } \\
\text { da própria } \\
\text { atividade } \\
\text { mental na } \\
\text { previsão da } \\
\text { atividade }\end{array}$ & $\begin{array}{l}\text { Consciência } \\
\text { da própria } \\
\text { atividade } \\
\text { mental na } \\
\text { descrição da } \\
\text { atividade }\end{array}$ & $\begin{array}{c}\text { Consciência } \\
\text { e/ou tomada } \\
\text { de } \\
\text { consciência } \\
\text { do processo } \\
\text { de resolução } \\
\text { da atividade }\end{array}$ \\
\hline $\begin{array}{c}\text { Indicadore } \\
\mathbf{s}\end{array}$ & $\begin{array}{c}\text { Primeiro nível: a } \\
\text { criança necessita } \\
\text { que as instruções } \\
\text { do adulto } \\
\text { acompanhem sua } \\
\text { tarefa } \\
\\
\text { Segundo nível: a } \\
\text { fala da própria } \\
\text { criança acompanha, } \\
\text { ou precede suas } \\
\text { ações durante a } \\
\text { tarefa } \\
\\
\text { Terceiro nível: a } \\
\text { criança realiza a } \\
\text { tarefa sem } \\
\text { necessitar do } \\
\text { acompanhamento } \\
\text { instrucional do } \\
\text { adulto nem da fala } \\
\text { para guiar suas } \\
\text { ações durante a } \\
\text { tarefa. }\end{array}$ & $\begin{array}{l}\text { Presença de } \\
\text { estratégias } \\
\text { orientadas } \\
\text { para um fim }\end{array}$ & $\begin{array}{c}\text { Referência a } \\
\text { procedimento } \\
\text { s } \\
\text { psicológicos } \\
\text { (internos) } \\
\text { e/ou técnicos } \\
\text { (externos) }\end{array}$ & \begin{tabular}{|c} 
Referência \\
ao produto, a \\
procedimento \\
s \\
psicológicos \\
(internos) \\
e/ou técnicos \\
(externos)
\end{tabular} & $\begin{array}{c}\text { Presença de } \\
\text { ações de } \\
\text { avaliação e } \\
\text { correção } \\
\text { incluídas na } \\
\text { descrição } \\
\text { das } \\
\text { atividades } \\
\text { ou } \\
\text { realizadas } \\
\text { durante a } \\
\text { descrição }\end{array}$ \\
\hline
\end{tabular}

\section{RESULTADOS E DISCUSSÃO}

As condições da atividade reflexiva e da regulação da conduta avaliadas apontaram, antes de mais nada, diferenças inter-individuais que, possivelmente, compõem as dinâmicas particulares de cada criança. A combinação diversificada de condutas nas várias categorias examinadas sugere estilos de funcionamento diferentes de cada sujeito com baixo rendimento escolar, que, supostamente, engendram avanços, retrocessos ou estabilidade psicológicos. Apesar disso, regularidades puderam ser observadas e encontraram, junto às referências teóricas deste estudo, sustentação para discussão. A partir da observação dos indicadores apresentados nas tabelas 1 e 2, foi possível formular as análises e conclusões seguintes.

Apenas a categoria atividade reflexiva sobre os conceitos científicos apresentouse homogênea quanto ao tipo de características encontradas nos diversos sujeitos com baixo rendimento escolar. No entanto, outras características também tiveram presença marcante no grupo de baixo rendimento escolar, tornando-se significativas para análise:

- $\quad \mathrm{Na}$ ativação da consciência reflexiva: presença, em todas as crianças de baixo rendimento escolar estudadas, de comportamento de ativação da consciência reflexiva, quaisquer que sejam as condições desta atividade. Significa dizer que todos os alunos de baixo rendimento escolar foram capazes de mobilizar atividade mental para providenciar respostas às perguntas auto-reflexivas, mesmo que as respostas não fossem avançadas no que se refere aos elementos utilizados.

- $\quad \mathrm{Na}$ atividade reflexiva sobre o próprio intelecto: ao conceituar atividade intelectual, as referências do grupo com baixo rendimento escolar eram, com freqüência (cinco, das seis crianças), restritas a elementos da vida escolar; freqüente ausência de consciência da própria atividade mental (cinco, das seis crianças); presença exclusiva neste grupo da noção de intelecto invariável apesar da concepção de aprendizagem controlável, como se fossem aspectos distintos (três, das seis crianças); presença exclusiva neste grupo da noção de controle da aprendizagem por insistência, por repetição (quatro, das seis crianças) e freqüente atribuição de competência de avaliação da aprendizagem a outrem, que não o próprio sujeito (três, das seis crianças). 
- Na atividade reflexiva sobre conceitos científicos: dificuldade de formação de conceitos em todos os sujeitos do grupo de baixo rendimento escolar.

- No processo de auto-regulação: igualmente heterogêneo em ambos os grupos, não se caracterizando como um processo diretamente determinante do rendimento escolar. No entanto, observou-se no grupo de baixo rendimento escolar, freqüente dificuldade de antecipar verbalmente as ações a serem encaminhadas em uma determinada tarefa (cinco, das seis crianças).

A consciência reflexiva foi avaliada em sua capacidade de ativação, em sua ação sobre o próprio intelecto e em sua ação sobre os conceitos científicos. Apresentou, na dimensão de ação sobre os conceitos científicos, uma diferença intergrupal significativa para discussão: o prejuízo da capacidade voluntária dos alunos com baixo rendimento escolar de formular explicações genéricas acerca de conhecimentos científicos que circulam no cotidiano escolar.

É interessante observar que todas as crianças do grupo de baixo rendimento foram capazes de ativar a consciência reflexiva quando solicitadas; algumas realizaram algum tipo de atividade reflexiva sobre o próprio intelecto, mas nenhuma teve êxito na atividade reflexiva sobre conceitos científicos, enquanto no outro grupo as formulações genéricas foram mais freqüentes. Significa dizer que, no grupo com baixo rendimento, todos os sujeitos apresentaram dificuldade de usar critérios conceituais para definir as disciplinas escolares. Algumas vezes os estudantes definiram-nas a partir das atividades mais comuns: (matem.) eu falo que é só ir fazendo umas conta [sic], quando a gente escreve, quando a gente termina assim a professora corrige e vê se está tudo certo... se estiver tudo certo ela manda a gente sentar e ficar com a cabeça baixa (1) / (port.) é uma coisa que a gente escreve, escreve pra copiar [sic] a lição que a professora passa, desenhar também às vezes, (ciênc.) a gente copia umas frase [sic] que a professora passa, (2) / (port.) fazer historinha, texto, escrever no caderno (3) / (matem.) ia poder fazer continha no caderno (4) / (matem.) eu ia explicar que era conta de mais, dividir, vezes (5) / (hist.) é ler livro, ler pra professora [sic], (6). Ou utilizaram explicações frágeis: eu ia falar bem assim, que a gente aprende mais a língua portuguesa e vai aprendendo porque quando a gente estuda vai aprendendo (1) / eu falava pra ela, era uma, é uma, tipo uma aula de português [sic] (2) / (geogr.) a gente tinha que escrever coisas de geografia, (ciênc.) tinha que copiar as coisas de ciências (3) / escrevendo... mostrando as matérias (5). Algumas vezes as definições foram formuladas por contraposição ou exclusão de ações: (matem.) a gente não escrevemo nada [sic], (2) / (port.) não é a mesma coisa que matemática, que no caderno de português não se faz continha [sic] (4). Outras vezes a confusão de elementos foi evidente: (port.) continha, é continha de vezes, de mais, de menos, só (6).

Já no grupo de alto rendimento escolar a maioria dos sujeitos apresentou critérios de distinção conceitual de ordem mais genérica: (matem.) vai trabalhar bastante com símbolos assim de mais, dividir, essas coisas, (geograf.) você trabalha muito com o sistema solar, você vai aprender mais sobre a Terra, aprende mais sobre planeta.(8) / (matem.) é os números, a gente vai aprender a contar, a fazer conta de dividir, de vezes, de mais, de menos e ...a tabuada, (hist.) sobre Pedro Álvares Cabral... aqueles pessoas bem antigo [sic] ...tempo antigo, do egípcio [sic], dos índios, (geogr.) a gente aprende sobre os planetas... o sol, a lua, os meteoros (ciênc.) vai mais o corpo humano, é as terras também, como faz adubo, como pranta [sic], (11) / (matem.) a gente faz em mais números [sic], (hist.) é uma, uma parte assim que a gente fala assim sobre os passados, né? Dos séculos..., (ciênc.) é quando a gente fala assim sobre... mais o corpo humano, sabe? (12). Os outros sujeitos deste grupo apresentaram referências específicas a temas das matérias: (hist.) onde escrevemos sobre os índios e colamos uns papéis que fala [sic] sobre urbano e rural, (geogr.) é onde colamos os mapas... que têm Paraná, outras cidades, Curitiba... (ciências) sobre a Terra (9) / (geogr.) é coisa assim de país, é mapa, essas coisas (10) ou a noção da distinção conceitual: cada coisa é diferente assim... é ciências e geografia é quase a mesma coisa, só que tem uma parte que é meio diferente assim (7).

O exame das dificuldades mais evidentes observadas na tarefa pedagógica, indicou o uso mais freqüente de elementos de conceito científico de aplicação coerente entre os sujeitos de alto rendimento: (por que devemos ferver o leite?) bactérias(7 e 11) / germe (8) / cólera (8, $9,12)$ / (o que é erosão?) buracos na terra (7) / enchente... abrindo a terra (10) / vento na rocha 
(11) / desmatamento destrói a terra e faz rachaduras (12) enquanto o outro grupo concentrou a maioria das respostas na categoria definição sem elementos de conceito científico: (por que devemos ferver o leite?) para toma café com leite [sic] (2) / para não aseda [sic] (5) / sinão fica frio [sic] (4) / poquete um Bicinho be tubo leite [sic] (porque tem um bichinho dentro do leite) (6) / (o que é erosão?) é uma palavra de Deus (3) / puti acona Bubi [sic] (explodir alguma coisa) (6). Desta forma, os grupos de rendimento escolar diverso apresentaram condutas marcadamente distintas na avaliação da atividade reflexiva sobre os conceitos científicos.

Examinando as condutas das crianças com baixo rendimento escolar foi possível observar que a dificuldade de formar conceitos científicos não impedia o sujeito de ter recursos para regular a própria conduta. No entanto, o avanço de qualidade desta regulação está vinculado à identificação consciente de funções mais complexas, envolvidas na formação de conceitos (abstração, generalização). A posterior tomada de consciência destes atos do próprio pensamento, seu isolamento e sua classificação permitirão ao sujeito o gerenciamento deliberado, auto-regulado do seu psiquismo (Vigotsky, 1982).

A atividade reflexiva sobre o próprio intelecto realizada pelos alunos com baixo rendimento escolar, sem o apoio da atividade reflexiva conceitual, caracteriza-se como uma atividade parcial, sustentada mais pela introspecção verbalizada, que permite identificar os processos internos, do que pela intelectualização, que permite compreendê-los e dominá-los (Vigotsky, 1987, p. 79).

Desta forma, a consciência da atividade mental, presente no grupo de baixo rendimento, parece se restringir a uma natureza limitada de percepção interior. A consciência da atividade mental, neste grupo, reflete uma percepção inespecífica da atividade interior: (...) eu penso na cabeça (2); (...) fiquei pensando e escrevendo (5), ou a consciência de funções básicas (percepção, atenção, memória), supostamente há muito tempo disponíveis: (...) ir pegando assim tipo com o olho mesmo e pensando, pensando muito com o olho [sic] (1). Este grau inicial de atividade auto-reflexiva é confirmado pela ausência de formulações genéricas acerca da atividade intelectual. A maioria das crianças apóia suas definições apenas em elementos da vida escolar.

Os avanços da percepção interior requerem uma maior intelectualização, abstração e generalização. Esta intelectualização permite, portanto, uma maior apuração na identificação das atividades internas, como é possível perceber em uma das crianças do grupo de alto rendimento: (...) Você tem um tanto certo de inteligência na tua cabeça. Só que daí você vai desenvolvendo... Quanto mais você vai aprendendo, mais você vai sabendo mais. Daí, por exemplo, tem uma parede, daí a parede vai destruindo, daí você vai sabendo mais ...o seu cérebro vai funcionando mais...; (...) montei uma mesa na imaginação e fiz (8).

Frente à condição deficitária da atividade reflexiva das crianças com baixo rendimento escolar, particularmente da atividade reflexiva sobre os conceitos científicos, o papel da escola precisa ser colocado em pauta: "(...) Os conceitos científicos, com o seu sistema hierárquico de inter-relações, parecem constituir o meio no qual a consciência e o domínio se desenvolvem, sendo mais tarde transferidos a outros conceitos e a outras áreas do pensamento." (Vigotsky, 1987, p. 79)

Quanto ao processo de lecto-escritura, uma outra perspectiva de compreensão precisa ser considerada no trabalho pedagógico. Apostando na linguagem como instrumento para organização do pensamento abstrato, as dificuldades de alfabetização, as mais apontadas pela escola, têm implicações incontestáveis sobre a formação dos conceitos científicos. O domínio da leitura e da escrita representa o domínio do código e o acesso aos significados a serem ordenados num sistema conceitual. A leitura cria este acesso, ao mesmo tempo que parece funcionar como "meio para centrar ativamente a atenção" (Vigotsky, 1987, p. 70) sobre significados selecionados.

Além destas observações é possível perceber a função intelectual exercida por estas competências instrumentais nas descrições de procedimentos feitas pelas crianças, quando ler ou escrever equivale a toda a atividade intelectual de reflexão, extração e inferência de informações envolvida no problema lógico: (...) vou copiar, copiar o nome do cachorro aqui , (...) eu fui lendo... (2); (...) eu, eu fiquei lendo (3); (...) tem que escrever os nome dos cachorro [sic] aqui (5); (...) aqui eu vou ter que escrever o nome do cachorro...tem que ver, ler assim, daí ver a raça (6). 
Outro conjunto de dados que revela a natureza intelectual das competências instrumentais escolares é extraído das entrevistas. As definições de atividade intelectual dadas pelas crianças evidenciam a centralidade destas competências: (inteligência) é ler (3); (...) tem que saber ler, escrever, pensar (5); (...) é aprender, ler, aprender as continha tudo certo (6); (é inteligente?) Hã, hã... porque eu não sabia ler, não sabia escrever e agora eu já sei (4).

Características particulares da atividade reflexiva sobre o intelecto também sugerem análise. Algumas das crianças com rendimento escolar inferior manifestaram a concepção de inteligência invariável, o que não foi observado no outro grupo. No entanto, a aprendizagem, no grupo de baixo rendimento, foi abordada como controlável pelo próprio sujeito, desvinculandose da inteligência. $O$ dado da estabilidade da inteligência é relevante na avaliação da regulação voluntária da conduta, uma vez que implica baixo investimento psicológico do sujeito no próprio crescimento intelectual (Tapia \& Garcia-Celay, 1996).

Indicando o comprometimento psicológico embutido nestas formas de percepção, a literatura também aponta para o meio social ao procurar alternativas de superação destas implicações: "Em conseqüência, o que haveria que fazer para melhorar a motivação das crianças seria ensinar-lhes a atribuir tanto os êxitos como os fracassos ao esforço, causa interna, provavelmente variável e controlável." (Tapia \& Garcia-Celay, 1996, p. 167).

A atribuição de competência de avaliação de resultados a outrem, freqüente entre as crianças repetentes e presente no outro grupo, também repercute nas possibilidades de avanço intelectual destes sujeitos. Leontiev (1978) contempla a percepção dos resultados da própria ação como determinante de mudanças de valor dos motivos que sustentam a atividade. Novas motivações podem surgir desta leitura do próprio desempenho e a atividade adquire, para o sujeito, um novo status. Assim se dá o crescimento psíquico. Piaget (1978) também concebe que "engajar-se na análise dos meios empregados" (p. 173) nas atividades constitui a essência do processo de compreensão do conhecimento envolvido.

Se as tarefas escolares são tarefas cujo êxito é julgado por outra pessoa, que não o próprio sujeito, como ele pode avaliar e redimensionar suas ações a fim de planejar novas ações, mais estratégicas, para uma próxima investida? Resta-lhe, talvez, usar o modelo de ensaio e erro como tentativa de alterar o julgamento alheio: (...) eu vou tentando ir fazer até a hora que eu conseguir (1); (...) É só eu ficar treinando, treinando bastante, daí eu consigo...leio umas três vezes...faço lição umas três vezes (3); (...) Daí eu soletrava, soletrava, depois eu tentava ler. Daí eu consegui (4).

A antecipação verbal do plano de ação, de ações estratégicas orientadas para um fim claro, compreendido pelo sujeito como meta, esteve pouco presente em ambos os grupos. Novamente a ação pedagógica é enfocada como provocadora desta conduta. Na dimensão escolar é preciso considerar o quanto o alheamento do sujeito acerca das finalidades de sua tarefa o debilita; o quanto o impede de guiar-se com segurança em sua trajetória educacional. É preciso encontrar na atividade pedagógica um planejamento estrutural que suponha um interlocutor inexperiente mas possuidor de conhecimentos prévios e, inicialmente desorientado, mas desejoso de direção, de antecipação intelectual dos fins de sua atividade mental, tal como posto por Gal'perin (1972) que, em seu estudo sobre a formação das ações mentais, identifica a criação da concepção preliminar da tarefa pelo professor como uma etapa relevante para o favorecimento da auto-regulação do sujeito.

O nível de regulação da fala, tão diversificado dentro dos grupos, mostrou não ser suficiente para a determinação do grau de regulação da conduta. As categorias de antecipação verbal de ações estratégicas, consciência da própria atividade mental na previsão e na descrição da atividade e consciência do processo de resolução se mostraram complementares na avaliação deste processo.

Partindo das regularidades observadas entre os sujeitos, cabia examinar se os processos psicológicos podiam estar agindo sobre seu rendimento escolar. E, confirmando a natureza interdependente da relação entre o processo ensino-apren-dizagem e 0 desenvolvimento, foi possível observar, também, os prováveis efeitos da escolaridade sobre os processos psicológicos dos estudantes. 
A finalidade deste estudo foi analisar a situação de alguns processos psicológicos de crianças com baixo rendimento escolar. Os resultados apresentados poderão contribuir com a discussão de possíveis determinações socioculturais desta situação e com o estabelecimento de procedimentos úteis na construção ou recuperação das competências destas crianças pela própria escola.

A diferença mais significativa encontrada entre os dois grupos de rendimento escolar foi no processo de formação de conceitos científicos. Tal diferença, no entanto, não vem para confirmar a idéia de que as crianças com baixo rendimento estejam desprovidas de processos intelectuais, presente nas explicações da comunidade escolar sobre o fracasso. Os resultados indicam, antes, que estes processos se encontram qualitativamente diferenciados dos de outras crianças. Ao chegarem à escola, as crianças apresentam conceitos de outra natureza (cotidianos - Vigotsky, 1987) e são capazes de promover atividade reflexiva sobre este tipo de conceito e sobre o próprio intelecto. A hierarquia e a subordinação de classes de significados, entretanto, são uma característica particular dos conceitos científicos, e é a esta natureza de construção intelectual que se refere a diferença entre grupos encontrada nesta investigação. Uma vez prejudicada a formação de conceitos científicos, o processo de intelectualização encontra-se também implicado (Vigotsky, 1987). Segue-se a limitação da atividade reflexiva e do movimento de auto-regulação que qualificam o pensamento e o conjunto do psiquismo.

Cabe recuperar, em Díaz et al. (1993), a diferenciação entre autocontrole, que é concebido como a capacidade de se comportar conforme instrução externa, e auto-regulação, que supõe a capacidade de planejar, dirigir e monitorar a própria conduta, adaptando-a às diversas circunstâncias. Se no autocontrole a direção é dada pelo instrutor e, posteriormente, reproduzida pelo próprio sujeito para resolver a tarefa, no processo de auto-regulação, a conduta é determinada por propósitos da própria criança. Há, neste caso, um planejamento de ação, cuja motivação se encontra no próprio sujeito e não mais, apenas, em contingências externas. Este processo muda radicalmente o rumo do desenvolvimento e da aprendizagem, impulsionados, então, pela autonomia intelectual conquistada. Tal nível de desenvolvimento da regulação da conduta requer o desenvolvimento de algumas funções psicológicas intelectivas e, especialmente, da consciência reflexiva, que orienta o movimento de auto-regulação. Sendo claro o prejuízo das atividades auto-reflexiva e conceitual dos estudantes em foco, é possível inferir a limitação das suas condições de auto-regulação aos aspectos reflexivos efetivamente conquistados, como, por exemplo, a consciência de ações externas (técnicas), ou de funções mais elementares como a percepção, a atenção e a memória.

Desta forma, compreende-se que, no processo ensino-aprendizagem, o sujeito não pode apenas ser exigido quanto à sua auto-regulação porquanto precisa, antes, dispor dos recursos e da direção da atividade de aprendizagem. Os recursos são constituídos no domínio das competências instrumentais (como a lecto-escritura) e da formação de conceitos, no reconhecimento dos processos psicológicos acionados ou a acionar na aprendizagem e numa auto-imagem de competência para o controle. A direção da atividade de aprendizagem é estabelecida na concepção preliminar da tarefa e na análise de seus resultados.

Algumas questões, no entanto, não foram respondidas por este estudo. Dentre elas: como as crianças com alto rendimento, mais novas e com menor tempo de experiência escolar, desenvolveram a atividade reflexiva sobre conceitos científicos? Qual a participação do contexto sociocultural nesta vantagem intelectual, uma vez que as crianças com baixo rendimento escolar demonstraram, de maneira geral, capacidade de ativar a consciência reflexiva, algumas inclusive sobre o próprio intelecto, mas não o fazem ao abordar conceitos científicos que, geralmente, são introduzidos pelo ambiente sociocultural escolar?

Algumas pistas para a compreensão destas questões podem ser levantadas. Paralelamente ao desenvolvimento das funções intelectuais e da consciência reflexiva, proporcionado pela atividade de aprendizagem escolar, formas específicas da interação social, escolar ou não, podem favorecer o avanço do domínio voluntário da conduta, remetendo ao âmbito familiar;

...los estudios de los estilos de los padres en la enseñanza de los niños y los modelos de crianza del niño, sugieren que son tres las características de la interacción entre el adulto y el niño que promueven capacidades relacionadas con las funciones autorregulatorias: el empleo del razonamiento y de las explicaciones verbales, el gradual abandono del control, y, combinado con ambas, un sentimiento 
de educación afectiva y calidez emocional. De hecho, esas tres son las variables que caracterizan a los padres de los niños que tienen una localización interna de control, esto es, niños que se ven a sí mismos como agentes que intervienen de manera activa y eficaz en su entorno. (Diaz et al., 1990, p. 168)

Há, ainda, os dados provenientes da fala dos professores e de algumas falas das crianças de baixo rendimento que se referem ao domínio de competências instrumentais como a leitura, a escrita e a operação de quantidades para avaliação do aproveitamento escolar, sugerindo que a atividade reflexiva e a auto-regulação, enfim a qualidade do pensamento, não sejam evidenciados como objetivos ou critérios escolares. Uma vez não enfocados, menor é a chance de que tenham, no início da vida escolar, sido mais ou menos estimulados a ponto de se diferenciarem rapidamente. Desta forma, o nascimento das diferenças no processo de formação de conceitos não parece ser produto exclusivo da intervenção pedagógica mas, antes, da ação de outras dimensões de interação social, como a família, não exploradas neste trabalho. A manutenção e/ou a intensificação de tais diferenças cognitivas pode, no entanto, ser responsabilidade do encaminhamento pedagógico.

Conforme o referencial teórico soviético, as competências pedagógicas participam da determinação de um psiquismo auto-regulado ao proporcionar atividades intelectuais que modificam a estrutura de conhecimento do sujeito a respeito do universo social e de si mesmo. O encaminhamento desorientado de tais atividades pode impedir o sujeito de construir instrumentos necessários a apropriações mais complexas, ou mesmo levá-lo ao fracasso escolar precoce.

Assim, é indispensável ao psicólogo que lida com educação conhecer estudos sobre a construção da leitura e da escrita, como os estudos psicogenéticos e cognitivistas; aprofundar a gênese e a dinâmica da operação de quantidades, como fazem os estudos da psicologia da educação matemática e, especialmente, ampliar a compreensão do processo de formação de conceitos científicos. Também cabe ao psicólogo considerar o favorecimento da atividade reflexiva e da auto-regula-ção pelas interações escolares, analisadas em estudos sociogenéticos.

O conhecimento psicológico precisa demonstrar a necessidade de um projeto pedagógico comprometido com a construção de um homem livre, gerente de seus rumos e de seu próprio psiquismo. Um homem que contribua voluntariamente com a coletividade. Um sujeito que, por prezar sua independência mental, perceba nessa natureza de liberdade uma meta social.

A criança que se enxerga nos descaminhos da construção intelectual, que anseia em dar um sentido próprio ao conhecimento que a humanidade acumulou, que pode dialogar consigo mesma durante a apropriação dos significados e que se aceita como interlocutora competente, tem mais chance de potencializar a ação de sua consciência e, portanto, de ser mais humana no uso de suas faculdades.

\section{REFERÊNCIAS BIBLIOGRÁFICAS}

Bassedas, E.; Huguet, T.; Marrodán, M.; Oliván, M.; Planas, M.; Rossell, M.; Seguer, M.; Vilella, M. (1996). Intervenção educativa e diagnóstico psicopedagógico. Porto Alegre: Artes Médicas.

Branco, A. U. (1993). Sociogênese e canalização cultural: contribuição à analise do contexto das salas de aula. Temas em Psicologia, 3, 9-17.

Cypel, S. (1986). Reflexões sobre alguns aspectos neurológicos de aprendizagem escolar. Coordenadoria de Estudos e Normas Pedagógicas de São Paulo- CENP, 1, 141-147.

Dantas, J. (1981). Desnutrição e aprendizagem. São Paulo: Ática.

Díaz, R. M.; Neal, C. J.; Amaya-Williams, M. (1993). Orígenes sociales de la autorregulación. Em L. C. Moll (Org.), Vigotsky y la educación: connotaciones y aplicaciones de la psicologia sociohistórica en la educación (p. 153-185). Buenos Aires: Aique Grupo Editor.

Freire, P. (1983). Educação e mudança. Rio de Janeiro: Paz e Terra.

Gal'perin, P. I. (1972). Estudio experimental de la formación de las acciones mentales. Em E. Stones (Org.), Psicologia de la educación .v. 1. (p. 170-184). Madri: Ediciones Morata. 
García, J. N. (1998). História e definições das dificuldades de aprendizagem. Em J. N. García, Manual de dificuldades de aprendizagem (p. 07-38). Porto Alegre: Artes Médicas.

Gil, M. S. C. A. (1993). A interação social na escola: professor e aluno construindo o processo ensino aprendizagem. Temas em psicologia,3, 29-40.

Kirby, J. R. (1984). Strategies and processes. Em J. R. Kirby (Ed.), Cognitive Strategies and educational performance (p. 3-12). London: Academic Press.

Lawson, M. J. (1984). Being executive about metacognition. Em J. R. Kirby (Ed.), Cognitive Strategies and educational performance (p. 3-12). London: Academic Press.

Leontiev, A. N. (1978). O desenvolvimento do psiquismo. Lisboa: Livros Horizonte Ltda.

Luria, A. R. (1987). Pensamento e linguagem: as últimas conferências de Luria. Porto Alegre: Artes Médicas.

Machado, A. M.; Souza, M. P. R.(Orgs.). (1997). Psicologia escolar: em busca de novos rumos. São Paulo: Casa do Psicólogo.

Masini, E. S. (1986). Problemas de aprendizagem - o que é isso? Confusões em um processo pouco conhecido. Boletim da Associação Brasileira de Psicopedagogia, 11, 31-41.

Merani, A. L. (1972). Desenvolvimento das funções neuro-psíquicas. Em A. L. Merani. Psicologia infantil. Rio de Janeiro: Paz e Terra.

Piaget, J. (1964). Development and learning. Journal of Research in Science Teaching, 11(3),176-186.

Piaget, J. (1977). A tomada de consciência. São Paulo: Melhoramentos: Ed. da Universidade de São Paulo.

Piaget, J. (1978). Fazer e compreender. São Paulo: Melhoramentos: EDUSP.

Rocha, E. M. B. (1980). O processo ensino aprendizagem: modelos e componentes. Em W. M. A. Penteado (Org.), Psicologia e ensino (p. 27-41). São Paulo: Papelivros.

Senf, G. M. (1986). Research in sociological and scientific perspective. Em J. K. Torgesen; B. Y. L. Wong (Eds.), Psychological and educational perspectives on learning disabilities. Florida: Academic Press Inc..

Sucupira, A. C. (1986). Hiperatividade: doença ou rótulo? Cadernos CEDES, 15, 30-43.

Tapia, J. A.; García-Celay, I. M. (1996). Motivação e aprendizagem escolar. Em C. Coll; J. Palacios; A. Marchesi (Orgs.), Desenvolvimento psicológico e educação: psicologia da educação (p. 161-175). v. 2. Porto Alegre: Artes Médicas.

Vigotsky, L.S. Estudio del desarrollo de los conceptos científicos en la edad infantil. Em L. S. Vigotsky, Obras escogidas (p. 181-286). v. 2. Madrid: Visor Distribuciones.

Vigotsky, L.S. (1984). Interação entre aprendizado e desenvolvimento. Em V. John-Steiner; E. Souberman; M. Cole; S. Scribner (Orgs.), Formação social da mente. São Paulo: Livraria Martins Fontes Editora.

Vigotsky, L.S. Pensamento e linguagem. São Paulo: Livraria Martins Fontes Ltda, 1987.

Wong, B.Y.L. (1986). Problems and issues in the definition of learning disability. Em J. K. Torgesen; B. Y. L. Wong (Eds.), Psychological and educational perspectives on learning disabilities. Florida: Academic Press Inc. 